\title{
Determination of total plasma oxysterols by enzymatic hydrolysis, solid phase extraction and liquid chromatography coupled to mass-spectrometry
}

\author{
Isabel Mendiara ${ }^{\mathrm{a}, \mathrm{d}}$, Celia Domeño ${ }^{\mathrm{a}}$, Cristina Nerín ${ }^{\mathrm{a}}$, Aron M. Geurts ${ }^{\mathrm{b}}$, Jesús Osada ${ }^{\mathrm{c}, \mathrm{d}, \mathrm{e}, \text {, }}$, \\ Roberto Martínez-Beamonte ${ }^{\mathrm{c}, \mathrm{d}, \mathrm{e}}$ \\ a Departmento de Química Analitica, Universidad de Zaragoza, Spain \\ ${ }^{\mathrm{b}}$ Human Molecular Genetics Center and Department of Physiology, Medical College of Wisconsin, Milwaukee, WI 53226, USA \\ c Departamento de Bioquímica y Biología Molecular y Celular, Facultad de Veterinaria, Instituto de Investigación Sanitaria de Aragón-Universidad de Zaragoza, Spain \\ d Instituto Agroalimentario de Aragón, CITA-Universidad de Zaragoza, Spain \\ e CIBER de Fisiopatología de la Obesidad y Nutrición, Instituto de Salud Carlos III, Spain
}

\section{A R T I C L E I N F O}

\section{Article history:}

Received 6 November 2017

Received in revised form 15 December 2017

Accepted 16 December 2017

Available online $\mathrm{xxx}$

\section{Keywords:}

Plasma analysis

24-hydroxycholesterol

25-hydroxycholesterol

27-hydroxycholesterol

LC-MS

Enzymatic hydrolysis

Cyp 7 b1 knock-out rat

\begin{abstract}
A B S T R A C T
The potential use of cholesterol esterases was tested to avoid alkaline hydrolysis for cleavage of plasma esterified oxysterols. The enzymatic hydrolysis was optimized by testing two sources of enzyme-Pseudomonas

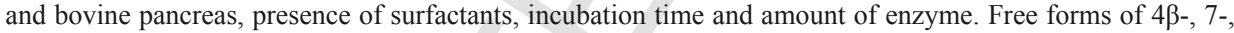
24-, 25- and 27-hydroxycholesterol (HC) as well 7-ketocholesterol (7-KC) were analyzed by liquid chromatography and mass-spectrometry using the deuterated internal standard, 25-HC(d6). Enzymatic hydrolysis was more effective using the Pseudomonas enzyme and in presence of surfactants. Compared to alkaline hydrolysis, it generated a cleaner chromatographic baseline and better recovery of the internal standard. Oxysterols were assayed with detection limits between 7 and $31 \mathrm{pg} / \mathrm{mL}$. Interassay coefficients of variation were lower than $10 \%$ and extraction recovery efficiencies, higher than $90 \%$. The procedure was used to characterize plasma levels of Cyp7b1-deficient rat, where it showed increased plasma levels of 7, 24 and 25-HC. Due to the low volume of sample required, it may be used in other animal models, particularly rodents, as well as in pediatric samples where sample amount is always a problem. Thus, the proposed new method offers mild enzymatic processing that greatly facilitates oxysterol determinations to delineate their role in physiopathology.
\end{abstract}

\section{Introduction}

Oxysterols, particularly those presenting the hydroxyl radical at positions 25 and 27 (Fig. 1), are enzymatically derived oxidation products of cholesterol that are lately being associated with highly prevalent diseases [1]. In this regard, as oxysterols are metabolites of cholesterol, they have mainly been studied in cardiovascular diseases [2]. When they accumulate, they have toxic effects on several cell types. For instance, 25-hydroxycholesterol (25-HC) and 7-ketocholesterol (7-KC) were shown to induce apoptosis of smooth muscle cells via the mitochondrial pathway and reactive oxygen species generation [3]. In macrophages, incubation with $25-\mathrm{HC}$ reportedly ac-

\footnotetext{
Abbreviation: 4- $\beta \mathrm{HC}, 4 \beta$-hydroxycholesterol; 7-HC, 7-hydroxycholesterol; 7-KC, 7-ketocholesterol; 24-HC, 24-hydroxycholesterol; 25-HC, 25-hydroxycholesterol; 27-HC, 27-hydroxycholesterol; LC-MS, liquid chromatography-mass spectrometry; SIR, single ion recording; SPE, solid phase extraction

* Corresponding author at: Department of Biochemistry and Molecular Biology, Veterinary School, University of Zaragoza, Miguel Servet 177, E-50013 Zaragoza, Spain.

Email address: Josada@unizar.es (J. Osada)
}

tivates stress response genes and reprograms protein translation, independently of liver $\mathrm{X}$ receptors and sterol-response element-binding proteins [4]. It has also been shown that the production of $25-\mathrm{HC}$ promotes the transformation of macrophages into foam cells in atherosclerotic plaques [5]. Moreover, 25-HC has been proposed to exert antiviral activity [6]. Likewise, oxysterols have been a matter of intense research in the nervous system, where their accumulation has been found to modify oxidative stress [7], apoptosis [8] and cell death in several types of neural cells such as PC12 cells $[9,10]$ and sympathetic [11], retinal [12] and cerebellar [13] neurons. 25-HC has also been proposed as a marker of Alzheimer's disease progression due to its ability to modulate choline acetyltransferase [14] and an etiological agent in amyotrophic lateral sclerosis [15]. Finally, 25-HC has been found to regulate the activity of estrogen receptors alpha and beta [16], which could cause reproductive disorders. Likewise, it has been reported to be involved in breast and ovarian cancer [2], as well as other types of cancer, and even in metastasis, through oxysterol binding protein $[17,18]$. Plasma $24-\mathrm{HC}$ and $27-\mathrm{HC}$ seem to be sensitive biomarkers for the evaluation of mild cognitive impairment and Alzheimer's disease [19]. Brain 7-KC, 7-HC and 4beta-HC levels have also been found associated with progression of this disease [20]. Furthermore, plasma 7-HC and 27-HC have been considered po- 
<smiles>CC(C)CCC[C@H]1CC[C@H]2[C@@H]3CC=C4C[C@@H](O)CC[C@]4(C)[C@H]3CC[C@]12C</smiles>

Cholesterol<smiles>CC(C)[C@H](O)CC[C@H](C)[C@H]1CC[C@H]2[C@@H]3CC=C4C[C@@H](O)CC[C@]4(C)[C@H]3CC[C@@]21C</smiles>

\section{4- hydroxycholesterol}<smiles>C[C@@H](CCCC(C)(C)O)[C@H]1CC[C@H]2[C@@H]3CC=C4C[C@@H](O)CC[C@]4(C)[C@H]3CC[C@@]21C</smiles>

25-hydroxycholesterol

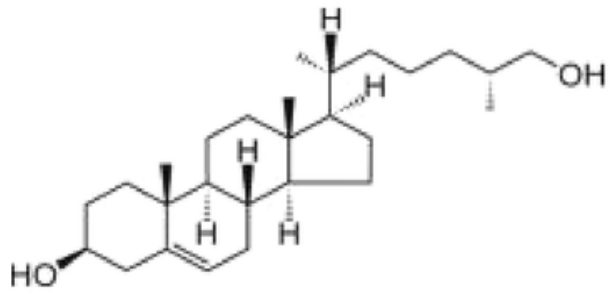

\section{7- hydroxycholesterol}

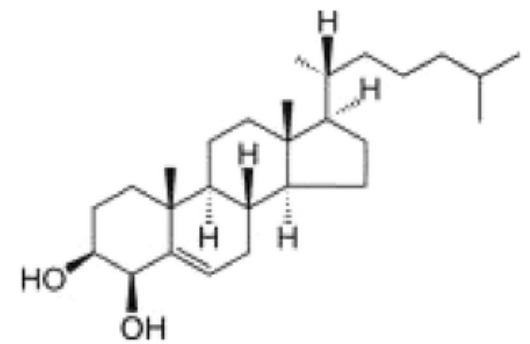

\section{$4 \beta$-hydroxycholesterol}<smiles>CC(C)CCC[C@H](C)[C@@H]1CC[C@H]2[C@@H]3[C@H](O)C=C4C[C@@H](O)CC[C@]4(C)[C@H]3CC[C@@]12C</smiles>

7a-hvdroxycholesterol

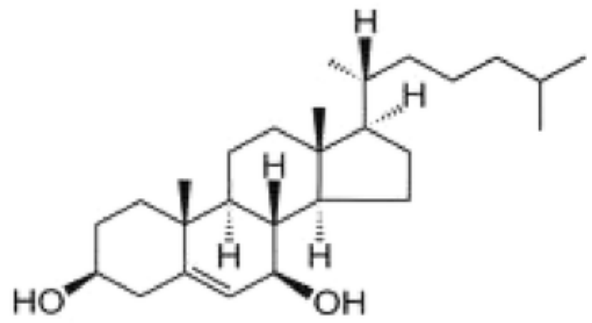

$7 \beta$-hydroxycholesterol

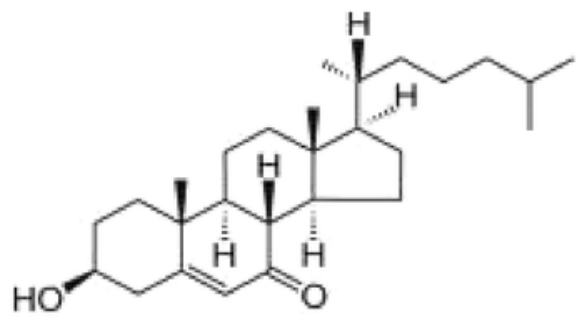

7-ketocholesterol

Fig. 1. Chemical structure of cholesterol and its oxysterol derivatives.

tential biomarkers of multiple sclerosis [21]. Plasma 4beta-HC has been proposed as a subrogate marker to assess hepatic CYP3A induction $[22,23]$.

Plasma levels of 25- and 27-hydroxycholesterol were similarly elevated in mice lacking oxysterol 7alpha-hydroxylase CYP7B1 [24]. Thus, it was proposed that this enzyme could have a major role in their metabolism. In contrast, patients displaying low CYP7B1 activity showed dramatic increases in plasma 25-HC levels and only moderate in those of $27-\mathrm{HC}$ [25]. These data indicate a preferential selectivity of the enzyme according to species. To further support this hypothesis, plasma oxysterol profile needs to be characterized in rats with inactivated Cyp $7 \mathrm{bl}$ gene.
Due to the above-mentioned findings, much interest has been devoted to improve the quantitation of oxysterols, which is complicated by their low plasma concentrations (in the range of $\mathrm{ng} \mathrm{mL}^{-1}$ ). In fact, cholesterol is approximately 1000 times more abundant than the next most abundant oxysterol [26]. Special efforts have been made to isolate the analytes from the plasma lipoproteins, their natural conveyance through the bloodstream. To this purpose, several extraction methods have been employed to remove interfering proteins $[27,28]$. Recently, the use of dichloromethane/methanol has been proposed to protect the sample and workers exposed to organic solvents [26]. Furthermore, their total quantification requires an alkaline hydrolysis step to transform oxysterol esters to free forms [29-33]. However, this alkaline hydrolysis not only has a serious drawback, since it re- 
duces sample integrity due to the degradation of triglycerides and phospholipids [26]; it also generates unspecific and undesirable products from 7-ketocholesterol in a time-dependent manner, which may interfere during the chromatographic analysis as a source of high backgrounds [34]. The release of fatty acids and generation of 7-ketocholesterol degradation products complicate the analysis [26] so to avoid these byproducts, a final step of purification by solid phase extraction (SPE) is usually undertaken. Sometimes, to increase the signal level of these metabolites, derivatizations are performed [35,36], which add another step to sample processing. The present manuscript successfully explores the use of cholesterol esterases to free esterified oxysterols and avoid the described complications when alkaline hydrolysis is used. In addition, the proposed new method greatly improves sample handling.

\section{Material and methods}

\subsection{Reagents}

Standards used were $4 \beta-\mathrm{HC}$ (99\% purity, CAS 17320-10-4), $7 \alpha-\mathrm{HC}$ (99\% purity, CAS 566-26-7), 73-HC (99\% purity, CAS 566-27-8), 7-keto cholesterol (99\% purity, CAS 566-28-9), 24(S)-HC (99\% purity, CAS 474-73-7), 25-HC (99\% purity, CAS 2140-46-7), 27-HC (99\%, CAS 20380-11-1), 25-HC(d6) (internal standard 99\%, CAS 88247-69-2) and 27-HC(d6) (internal standard 99\%, CAS 1246302-95-3), purchased from Avanti Polar Lipids (Alabaster, AL, USA). Cholesteryl stearate (96\%, CAS 35602-69-8), potassium hydroxide (85\%, CAS 1310-58-3), butylated hydroxytoluene (BHT) (99\%, CAS 128-37-0) and Triton X-100 (99\%, CAS 9002-93-1) were purchased from Sigma-Aldrich (Madrid, Spain). Except cholesteryl stearate, which was dissolved in hexane, all standard solutions were prepared in methanol at a concentration of $1 \mathrm{mg} \mathrm{mL}^{-1}$ and stored at $-20^{\circ} \mathrm{C}$. Cholesterol esterases from Pseudomonas sp. (CAS 9026-00-0) and from bovine pancreas (CAS 9026-00-0) were purchased from Invitrogen (Barcelona, Spain) and prepared at a concentration of $200 \mathrm{U} / \mathrm{mL}$ in $0.1 \mathrm{M}$ potassium phosphate $\left(\mathrm{KH}_{2} \mathrm{PO}_{4}\right), 0.05 \mathrm{M}$ sodium chloride, $5 \mathrm{mM}$ cholic acid and $0.1 \%$ Triton $\mathrm{X}-100$. Solvents used, such as methanol (analytical grade LC-MS, CAS 67-56-1), ethanol (analytical HPLC grade CAS 67-63-0), chloroform (analytical HPLC grade CAS 67-66-3) and hexane (96\%; CAS 110-54-3), were provided by Sharlab (Barcelona, Spain). Water was supplied by a Milli-Q Plus 186 (Millipore, Billerica, MS, USA) system.

\subsection{Sample handling}

Cyp7b1-deficient (knock-out or $\mathrm{KO}$ ) rats were purchased from Transposagen BioPharmaceuticals (Lexington, KY, U.S.A). These rats were generated by transposon-mediated gene-trap insertional mutagenesis in the Fischer F344 strain [37] at the Medical College of Wisconsin under protocols approved by the Institutional Animal Care and Use Committee (IACUC). A single male offspring was identified harboring a gene-trap transposon insertion in the first intron of $C y p 7 b 1$ that was predicted to truncate normal transcription. This male was backcrossed to the Fisher 344 strain and heterozygous carriers were intercrossed to generate homozygous animals for experiments. A three-primer assay using primers B3-306 F: 5'-AAACATCACCTTCTGCAGAGGAC-3', B3-306_R: 5'-CCCTATTTGTATCTTGCTCAGCTTT-3', and ITR-L: 5'-CCTAACTGACTTGCCAAAAC-3' were used to confirm the gene-trap insertion and genotype the animals for zygosity. No message was observed by RT-PCR in any of the tissues studied (data not shown).
Blood from male wild-type (WT) Fisher 344 and homozygous Cyp 7b1-deficient rats on chow diet was obtained by intracardiac puncture from left ventricle in $\mathrm{CO}_{2}$-euthanized animals. Identical procedure was used to obtain blood from Apoe-deficient mice on chow diet as well. A volunteer subject consented to give his blood for the experiment once used for a medical revision. The protocol was approved by the Ethics Committee for Animal Research of the University of Zaragoza. Blood $(1 \mathrm{~mL})$ was immediately mixed with $6 \mu \mathrm{L}$ of $0.5 \mathrm{M}$ EDTA dissolved in phosphate-buffered saline (PBS). Blood tubes were kept on ice and centrifuged at $1150 \mathrm{~g}$ for $10 \mathrm{~min}$ to separate plasma. The latter was aliquoted, deep-frozen in liquid nitrogen and stored at $-80^{\circ} \mathrm{C}$ until further processing. Samples, thawed on crushed ice, were processed without breaking the cold chain.

\subsection{Determination of oxysterols}

\subsubsection{Free oxysterols}

Three extraction methods were tested: those of Folch et al. [28] and Bligh and Dyer [27], and that described by McDonald et al. [26], being the Folch the most effective in terms of extraction recovery and quality. Briefly, $100 \mu \mathrm{L}$ of rat plasma were placed in capped $10 \mathrm{~mL}$ glass tubes, to which $0.75 \mathrm{~mL}$ of chloroform/methanol $(2: 1, \mathrm{v} / \mathrm{v}) \mathrm{mix}-$ ture containing $4.5 \mu \mathrm{L}$ of $9.5 \mu \mathrm{g} \mathrm{mL}^{-1} 25-\mathrm{HC}(\mathrm{d} 6)$ as internal standard and $6.5 \mu \mathrm{L}$ of $1150 \mu \mathrm{g} \mathrm{mL}^{-1}$ BHT, both in methanol, were added. Then, $0.25 \mathrm{~mL}$ of chloroform were added and homogenized. Finally, $0.25 \mathrm{~mL}$ of Milli-Q water were mixed by shaking for $10 \mathrm{~min}$. The mixture was centrifuged at $622 \mathrm{~g}$ for $10 \mathrm{~min}$ and the lower organic phase was recovered. Two further cycles of extraction, homogenization and centrifugation were carried out. Combined organic phases were evaporated to dryness under $\mathrm{N}_{2}$ stream at $40^{\circ} \mathrm{C}$. Solid extracts were dissolved in $1 \mathrm{~mL}$ of hexane with the aid of sonication for $5 \mathrm{~min}$.

\subsubsection{Total oxysterols: alkaline hydrolysis}

To cleave oxysterol-fatty acid conjugates, two different alkaline hydrolysis procedures were applied to the combined organic phases, that described by DeBarber et al. [32] and the more sterol-specific alkaline hydrolysis method proposed by McDonald et al. [26]. A summary of steps in all procedures is shown in Fig. 2.

\subsubsection{Total oxysterols: enzymatic hydrolysis}

After optimization, the best experimental conditions were set up as follows: $100 \mu \mathrm{L}$ of plasma were carefully mixed with $100 \mu \mathrm{L}$ of potassium phosphate $(\mathrm{pH} 7.4,0.5 \mathrm{M}$ ) containing $0.25 \mathrm{M} \mathrm{NaCl}, 25 \mathrm{mM}$ cholic acid and $0.5 \%$ Triton ${ }^{\circledR} \mathrm{X}-100$ and 1.6 units of Pseudomonas cholesterol esterase in a $0.2 \mathrm{~mL}$ tube. Samples were incubated at $37^{\circ} \mathrm{C}$ for $60 \mathrm{~min}$ in a Biorad thermal cycler (Hercules, CA, USA). After the enzymatic hydrolysis, samples underwent free oxysterol quantification.

\subsection{Solid phase extraction}

Samples were purified by solid phase extraction (SPE) MFE $^{\circledR}$-PAK Amino cartridges $(500 \mathrm{mg} / 3 \mathrm{~mL}$ ) (Análisis Vínicos, S.L, Tomelloso, Ciudad Real, Spain) using a manifold system from Waters (Milford, MA, USA). Vacuum was adjusted to maintain a flow of $1.0-1.5 \mathrm{~mL} / \mathrm{min}$. Solvents and conditions are described in supplemental Table 1. Eluted samples were evaporated to dryness under $\mathrm{N}_{2}$ stream at $40^{\circ} \mathrm{C}$ and then dissolved in $0.12 \mathrm{~mL}$ of methanol/Milli-Q water $(9: 1, \mathrm{v} / \mathrm{v})$ with sonication for $5 \mathrm{~min}$. 


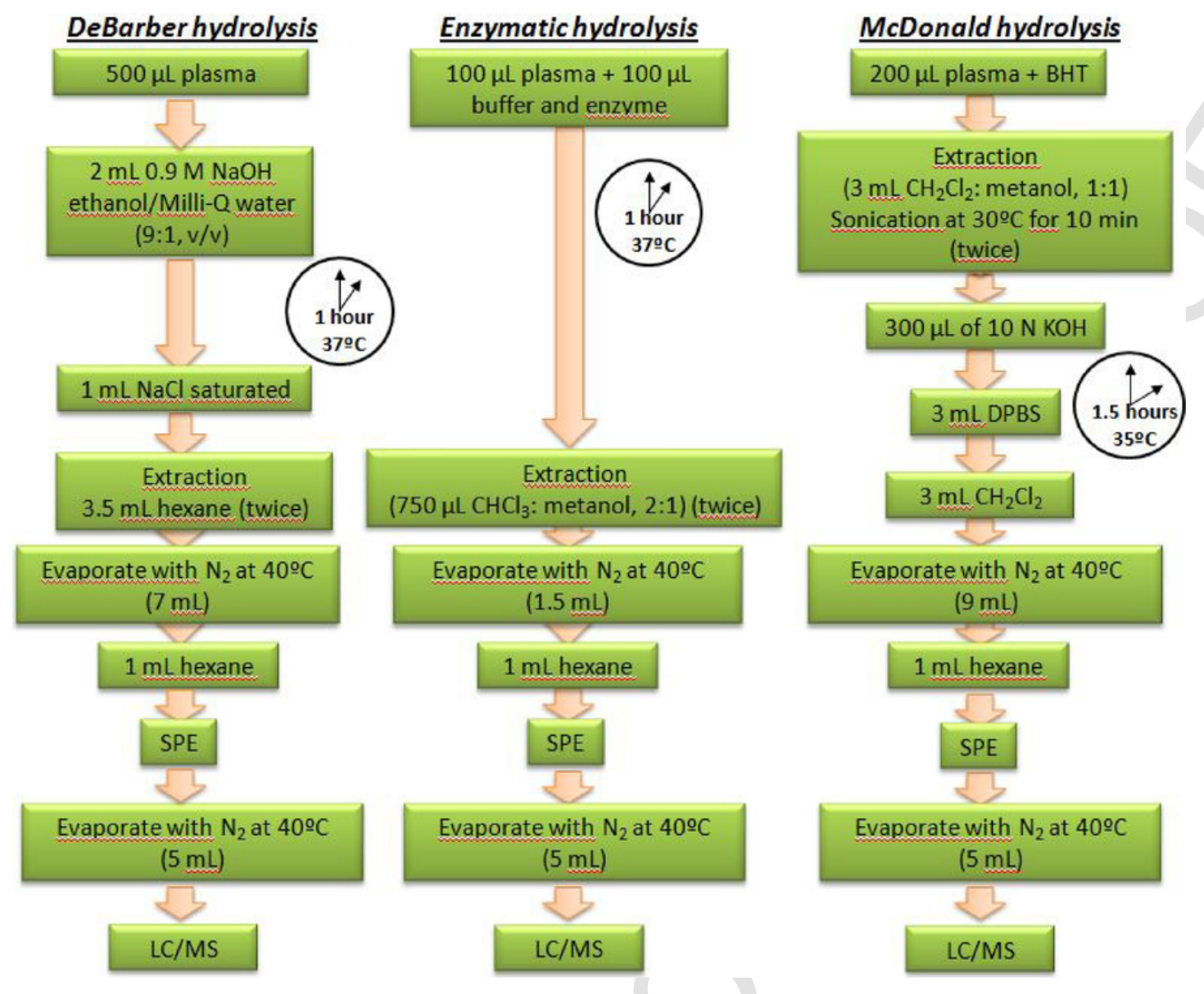

Fig. 2. Overview of compared analytical methods.

\subsection{LC/MS analysis}

An ultra-high resolution ACQUITY UPLC ${ }^{\text {TM }}$ H-Class liquid chromatograph from Waters (Milford, MA, USA) equipped with an ACQUITY UPLC ${ }^{\text {TM }}$ BEH C18 $2.1 \mathrm{~mm} \times 150 \mathrm{~mm}$ column and $1.7 \mu \mathrm{m}$ particle diameter was used. Mobile phases were $0.1 \%$ formic acid in methanol (v/v) (A) and $0.1 \%$ formic acid in Milli-Q water (v/v) (B). The flow was set at $0.3 \mathrm{~mL} / \mathrm{min}$. Injection volume was $20 \mu \mathrm{L}$. Temperatures of column and samples were 40 and $10^{\circ} \mathrm{C}$, respectively. The chromatograph was coupled to an ACQUITY TQD ${ }^{\mathrm{TM}}$ tandem quadrupole detector mass spectrometer operating as a single analyzer from Waters. Gradient and detection conditions are shown in Table 1. The selected $\mathrm{m} / \mathrm{z}$ values and used operational conditions for the different compounds are shown in supplemental Table 2. All data were acquired and processed using MassLynx v4.1 (Waters).

\subsection{Analytical features}

The stock solutions for $25-\mathrm{HC}, 24(\mathrm{~S})-\mathrm{HC}, 27-\mathrm{HC}, 7 \alpha-\mathrm{HC}, 7 \beta-\mathrm{HC}$, $4 \beta-\mathrm{HC}$ and 7-ketocholesterol were prepared in methanol at concentration of $1 \mathrm{mg} \mathrm{mL}^{-1}$. The working internal standard (IS) solutions for $25-\mathrm{HC}(\mathrm{d} 6)$ and $27-\mathrm{HC}(\mathrm{d} 6)$ were prepared at the same concentration. All solutions were stored in glass tubes protected from light at $-20^{\circ} \mathrm{C}$. Calibration curves were freshly prepared for each batch in methanol and MilliQ water $(9: 1, \mathrm{v} / \mathrm{v})$, same solvent as final sample solvent. The final concentration for the calibration standards of each compound were $1,2,4,20,80,150,400$ and $2000 \mathrm{ng} \cdot \mathrm{mL}^{-1}$. All of
Table 1

Experimental conditions for the quantification of oxysterols in plasma.

\begin{tabular}{lll}
\hline LC & Time $(\min )$ & Solvent A $(\%, \mathrm{v} / \mathrm{v})$ \\
\hline Gradient & 0.00 & 70 \\
& 2.00 & 70 \\
& 2.10 & 85 \\
& 4.00 & 85 \\
& 14.00 & 100 \\
& 19.00 & 100 \\
& 19.10 & 70 \\
MS & 22.00 & 70 \\
Source & & \\
Detection mode & Electrospray & \\
Ionization & SIR & \\
Capillary voltage & positive & \\
Desolvation temperature & $3 \mathrm{kV}$ & \\
Desolvation gas flow & $650^{\circ} \mathrm{C}$ & \\
Cone gas flow & $600 \mathrm{~L} / \mathrm{h}$ & \\
Source temperature & $40 \mathrm{~L} / \mathrm{h}$ & \\
\hline
\end{tabular}

them were spiked with both IS at $150 \mathrm{ng} \cdot \mathrm{mL}^{-1}$ each one. The linear dynamic range was determined from the triplicate response of oxysterol solutions at different concentrations. Limits of detection $(\mathrm{LOD})=3 \mathrm{SD}$ of blank/slope of calibrators and of quantification $(\mathrm{LOQ})=3.2 \mathrm{LOD}$ were obtained. The determination of intra-day $(n=5)$ and inter-day $(n=15)$ precisions, the recovery and accuracy of the method were carried out by analyzing plasma spiked with $100 \mathrm{ng} \mathrm{mL}^{-1}$ of different oxysterols. Matrix effects were investigated 
by a post-extraction addition procedure, as described by Trufelli et al. [38]. Basically, four sets of samples were analyzed: a standard solution with a known concentration (set A), plasma samples spiked with the same amount of analytes after the sample treatment (set B), plasma samples spiked with the same amount of analytes before the sample treatment (setC) and non-spiked plasma samples (set D), to subtract the endogenous concentration levels. The response of the analytes was used in the following equations to quantify the matrix effects (Eq. (1)), the extraction recovery (equation 2 ) and the process efficiency (Eq. (3)).

$$
\text { Matrix effects }(\%)=100 \times(B-D) / A
$$

Extraction recovery $(\%)=100 \times(\mathrm{C}-\mathrm{D}) /(\mathrm{B}-\mathrm{D})$

$$
\text { Process efficiency }(\%)=100 \times(C-D) / A
$$

\subsection{Statistical analyses}

Results are shown as means \pm standard deviation of the values. The data were analyzed using the Prism 5.02 software for Windows (GraphPad, S. Diego, CA, USA). Comparisons were carried out using one-way ANOVA and Bonferroni post-hoc test. The statistical significance was set at $\mathrm{p}<0.05$.

\section{Results}

\subsection{Initial chromatographic and mass-spectrometric settings}

When electrospray ionization is utilized, ammonium adduct formation of sterols is dependent on the mass spectrometer and, more importantly, the ionization source used $[26,39,40]$. To avoid operating problems involving the mass spectrometer, our equipment required temperatures higher than $50^{\circ} \mathrm{C}$. With the source temperature set at $120^{\circ} \mathrm{C}$, the spectra obtained in presence of ammonium salts are shown in supplemental Fig. 1. As can be observed, no ammonium adducts were formed (expected at $\mathrm{m} / \mathrm{z} 420.3$ ). At this point, fragments corresponding to $\mathrm{m} / \mathrm{z} 385.3$ and 367.3 , also formed without adding ammonium acetate, were selected for alternative monitoring. To explore their potential use, several chromatographic conditions were tested (data not shown). In fact, as depicted in supplemental Fig. 2, the use of gradients containing acetonitrile and ammonium salts decreased the signals and retarded elution times of 25- and 27-HC when compared to $0.1 \%$ formic acid in methanol-Milli-Q water gradients. The use of ACQUITY UPLC ${ }^{\text {TM }}$ BEH C18 $2.1 \mathrm{~mm} \times 150 \mathrm{~mm}$ column in our chromatographic conditions together with single ion recording allows rapid and specific determinations of 4 $\beta-, 7-, 24-, 25-$ and $27-\mathrm{HC}$ as well as $7-\mathrm{KC}$ without derivatization and even the use of $25-\mathrm{HC}(\mathrm{d} 6)$ as internal standard (Supplemental Fig. 3 and Supplemental Table 2). In these chromatographic conditions, 22-HC was also separated (Supplemental Fig. 3).

\subsection{Preliminary exploration of cholesterol esterases to hydrolyze hydroxycholesterol esters}

As shown in supplemental Fig. 4, plasma incubation with the enzyme increased the levels of 25 and $27-\mathrm{HC}$ in each group of rats compared to plasma without enzyme. The addition of Triton X-100 as surfactant further increased the concentrations. These results clearly indicate that the enzymatic approach is a promising method for hydroxycholesterol ester cleavage and that the presence of a surfactant facilitates the action of the enzyme.

Two sources of cholesterol esterase were tested to assess their ability to cleave hydroxycholesterol esters, one from Pseudomonas and the other from bovine pancreas. Despite the fact that both enzymes have been reported to have similar activity regarding cholesterol esters [41], a different behavior was observed with oxysterols. The use of Pseudomonas enzyme resulted in a stronger signal for both 25- and 27-HC (data not shown).

Representative chromatograms displaying the completeness of cholesterol ester hydrolysis under different experimental conditions are reproduced in Fig. 3. They show that increasing the amount of enzyme reduced the amount of cholesteryl esters present after a $120 \mathrm{~min}$ incubation time. In fact, $1.6 \mathrm{U}$ of the Pseudomonas enzyme was able to hydrolyze all the cholesteryl esters in the sample. A similar result was obtained using the DeBarber et al. procedure [32]. In contrast, the alkaline hydrolysis proposed by Mcdonald et al. [26] did not achieve a complete hydrolysis of cholesterol esters. Overall, these results indicate that Pseudomonas enzyme is perfectly active on its proper substrate and that increasing amounts of enzyme favors complete hydrolysis.

\subsection{Comparison of enzymatic and alkaline hydrolysis procedures}

Once verified the feasibility of the use of cholesterol esterases to hydrolyze oxysterol esters, the enzymatic procedure was compared to conventional alkaline hydrolysis in terms of chromatographic background. Fig. 4 displays the chromatograms obtained following both hydrolysis procedures. It is noteworthy that the enzymatic hydrolysis resulted in a cleaner chromatogram with fewer unknown compounds than the alkaline hydrolysis. These methods were also compared in terms of recovery of the internal standard, 25-HC(d6), spiked before processing. As shown in Supplemental Fig. 5, both alkaline procedures, as proposed by DeBarber et al. [32] and McDonald et al. [26], resulted in similar recoveries and not significantly different from those obtained by the enzymatic treatment. The latter recovery was close to the values obtained for samples without hydrolysis. Thus, the enzymatic procedure induces fewer unknown compounds and results in similar recoveries compared to alkaline methods.

\subsection{Analytical features}

As shown in Table 2, using the enzymatic method, the LOD were less than $54 \mathrm{pg} \mathrm{mL}^{-1}$ and the LOQ was lower than $171 \mathrm{pg} \mathrm{mL}^{-1}$ for all the assayed oxysterols. Intra-day precision values were less than $5 \%$ except for $27-\mathrm{HC}$ and $7-\mathrm{KC}$. Inter-day precisions were lower than $10 \%$ for the different oxysterols. The process efficiencies were around $90 \%$ except for 7-HC. Analytical features for alkaline hydrolysis using the DeBarber et al. method [32] are also included in Table 2. The LOD was never lower than $325 \mathrm{pg} \mathrm{mL}^{-1}$ and the LOQ was lower than $1000 \mathrm{pg} \mathrm{mL}^{-1}$. Intra-day precision values were higher than $6 \%$, and inter-day precision was higher than $10 \%$ for all assayed oxysterols. The process efficiencies were lower than $90 \%$ except for $25-\mathrm{HC}$ and $7-\mathrm{HC}$. These results indicate that the enzymatic hydrolysis provides better sensitivity and accuracy than the alkaline hydrolysis. 


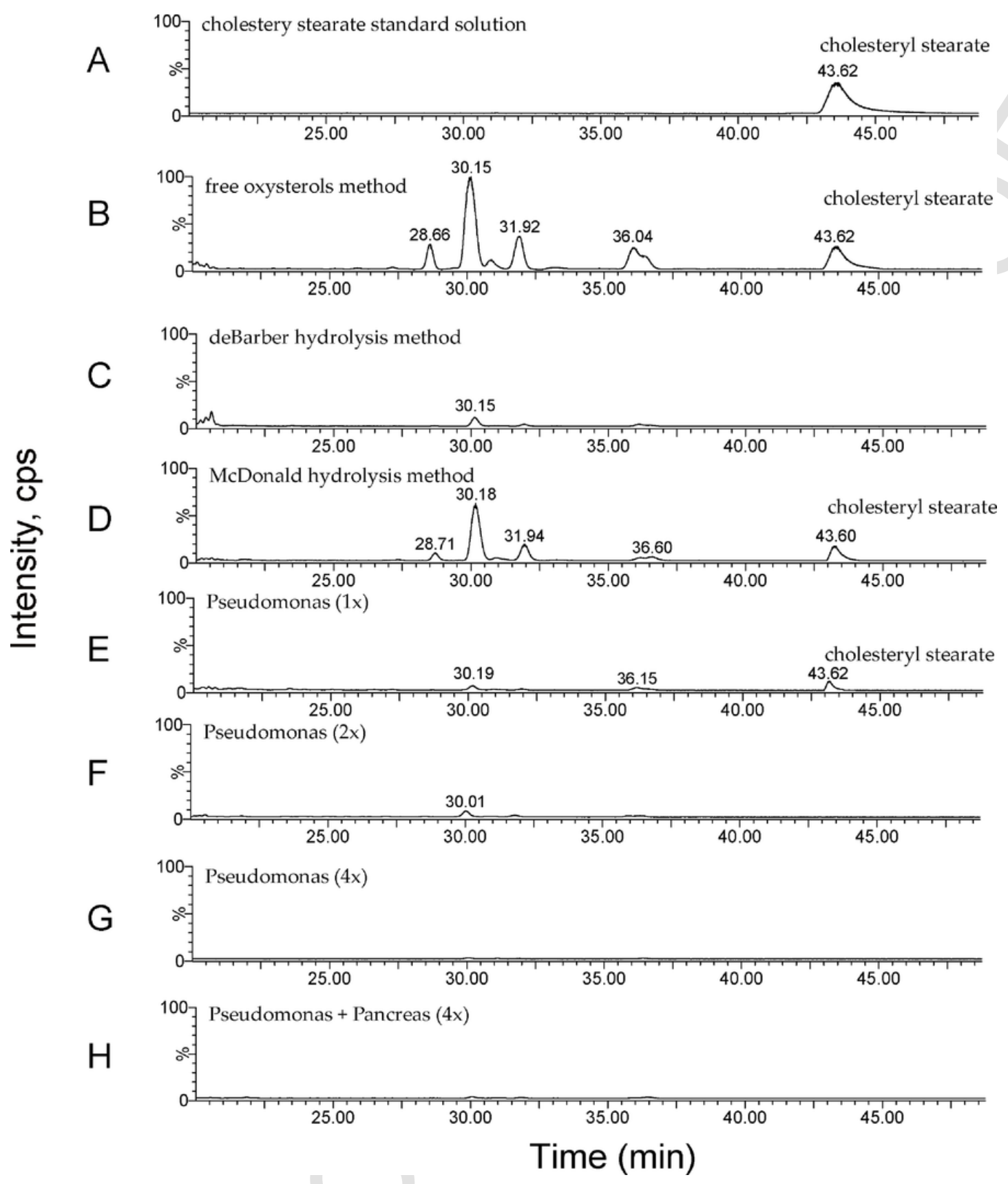

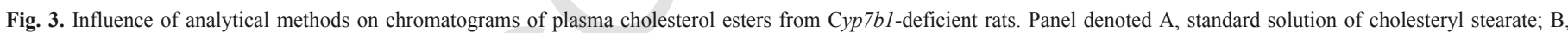

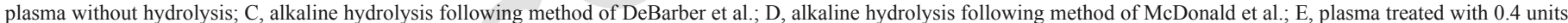

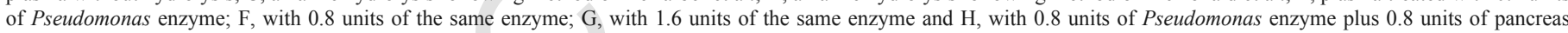
enzyme. All enzymatic assays were carried out at $37^{\circ} \mathrm{C}$ for $120 \mathrm{~min}$.

\subsection{Comparison of enzymatic and alkaline hydrolysis procedures for oxysterol quantification}

The results obtained for 4 $4-, 7-, 24-, 25-$ and $27-\mathrm{HC}$ as well as 7-KC from Cyp7b1-deficient rats are shown in Fig. 5. As can be observed, the concentrations of both unesterified 25- and 27-HC were similar and higher than that of 24-HC. Concentrations of unesterified $4 \beta$ - and 7-HC were similar and higher than that of 7-KC.

Despite the fact that both alkaline hydrolysis methods gave similar contents of total $27-\mathrm{HC}$ and $7-\mathrm{HC}$ to the enzymatic, they only dif- fered in the amount of $25-\mathrm{HC}$ detected, the McDonald protocol resulted in lower levels of 25-HC than DeBarber. No 24-HC was detected with the alkaline hydrolysis procedures and the amount of 7-KC was particularly high and that of $4 \beta-\mathrm{HC}$ remarkably low using the DeBarber protocol. These results indicate that the amount of $24-\mathrm{HC}$ was strongly influenced by the alkaline hydrolysis procedure used and that the profile of other oxysterols is also influenced by alkaline conditions.

Quantification of levels of oxysterols in different species is shown in Table 3. Cyp7b1-deficient rats showed increased plasma levels of 7-HC, 24-HC and 25-HC. Rodents showed decreased levels of 


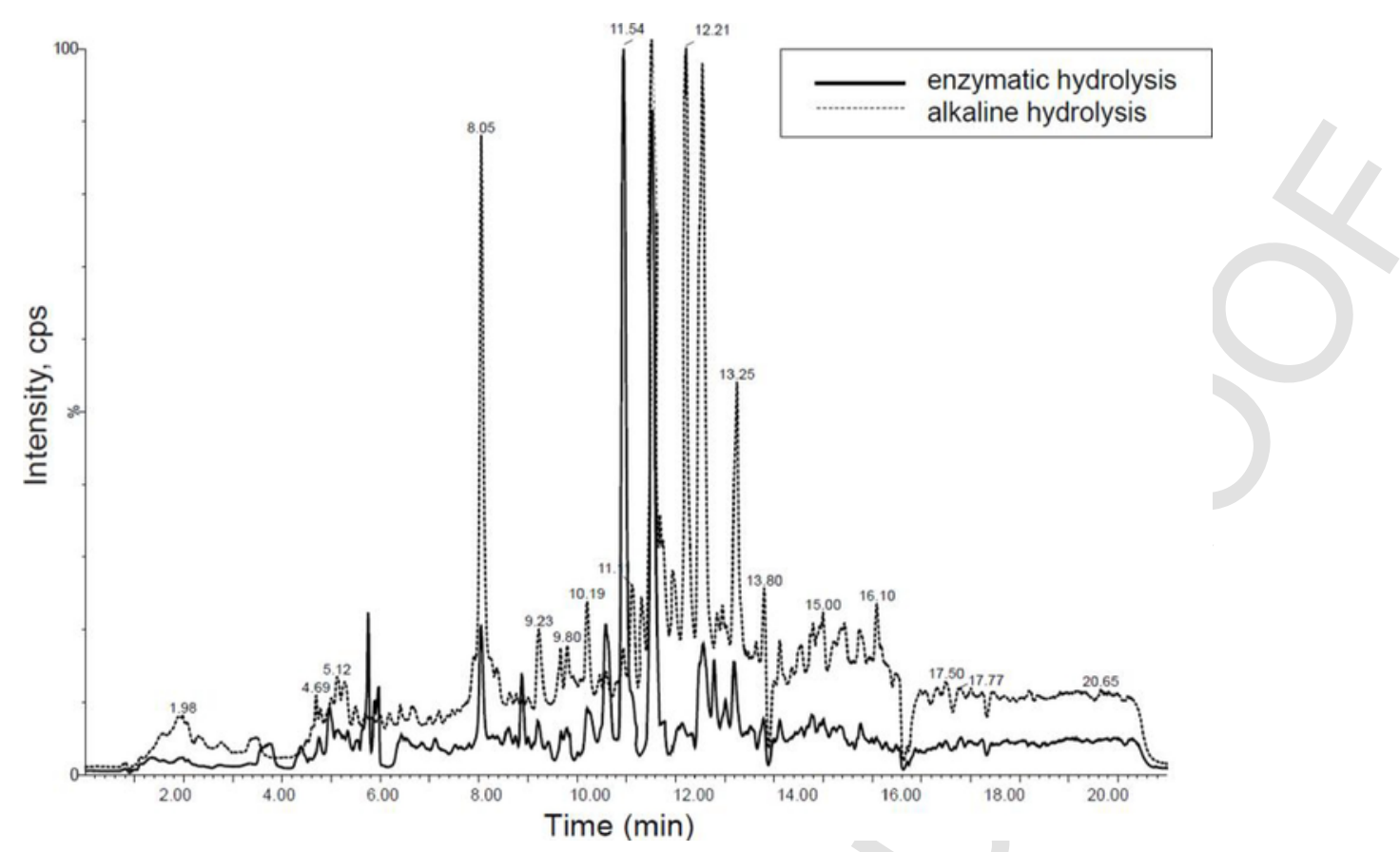

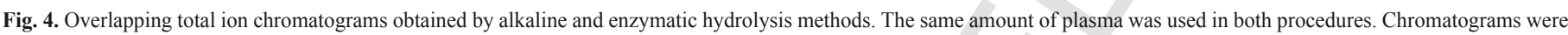
acquired using SIR mode.

Table 2

Analytical parameters of the enzymatic and alkaline (deBarber et al.) hydrolysis methods for total oxysterols.

\begin{tabular}{|c|c|c|c|c|c|c|}
\hline & 24-HC & $25-\mathrm{HC}$ & 27-HC & 7-HC & 7-KC & $4-\beta \mathrm{HC}$ \\
\hline \multicolumn{7}{|l|}{ Enzymatic } \\
\hline $\mathrm{LOD}(\mathrm{pg} / \mathrm{mL})$ & 7 & 10 & 20 & 53 & 31 & 15 \\
\hline $\mathrm{LOQ}(\mathrm{pg} / \mathrm{mL})$ & 22.4 & 32 & 64 & 170 & 99 & 48 \\
\hline $\begin{array}{l}\text { Intra-day precision }\left(\mathrm{RSD}^{0} \text {, }\right. \\
\mathrm{n}=5 \text { ) }\end{array}$ & 4.92 & 3.86 & 6.64 & 4.77 & 8.46 & 4.40 \\
\hline $\begin{array}{l}\text { Inter-day precision }(\mathrm{RSD} \% \text {, } \\
\mathrm{n}=15)\end{array}$ & 8.20 & 6.35 & 9.76 & 7.94 & 9.28 & 7.28 \\
\hline $\begin{array}{l}\text { Process efficiency }(\%) \\
\text { Alkaline }\end{array}$ & 93.50 & 91.29 & 90.02 & 75.82 & 95.78 & 89.17 \\
\hline $\mathrm{LOD}(\mathrm{pg} / \mathrm{mL})$ & 325 & 400 & 515 & 718 & 625 & 700 \\
\hline LOQ $(\mathrm{pg} / \mathrm{mL})$ & 1040 & 1284 & 1647 & 2297 & 2000 & 2242 \\
\hline $\begin{array}{l}\text { Intra-day precision }(\mathrm{RSD} \% \text {, } \\
\mathrm{n}=5 \text { ) }\end{array}$ & 7.83 & 6.78 & 9.02 & 8.67 & 11.84 & 8.26 \\
\hline $\begin{array}{l}\text { Inter-day precision (RSD } \% \text {, } \\
n=15)\end{array}$ & 12.56 & 10.53 & 11.25 & 14.16 & 11.36 & 13.26 \\
\hline Process efficiency $(\%)$ & 82.14 & 90.57 & 81.40 & 94.51 & 78.48 & 87.17 \\
\hline
\end{tabular}

The determination of intra-day and inter-day precisions, the recovery and accuracy of the method were carried out by analyzing plasma spiked with $100 \mathrm{ng} \cdot \mathrm{mL}^{-1}$ of different oxysterols.

24-HC compared to the human plasma. Notable difference was observed regarding $27-\mathrm{HC}$ among rat strains.

\section{Discussion}

To reduce the unknown compounds generated during alkaline hydrolysis, due to the basic environment and high temperatures, and to shorten the sample processing time, a new procedure has been developed and optimized that makes use of the ability of cholesterol esterases to hydrolyze hydroxycholesterol esters. The proposed method may be considered as an improvement over previous approaches using chemical hydrolysis, as it offers the following advantages. First, it generates fewer unknown compounds since less sterol degradation was observed. Second, it shows a $90 \%$ recovery of the internal standard. Third, it allows the simultaneous determination of several oxysterols with acceptable analytical goals. The proposed method shows an improvement in the LOD and LOQ over conventional protocols involving alkaline hydrolysis. Indeed, it requires less sample volume what makes suitable for small animals or pediatrics medicine. Fourth, it requires less sample manipulation by eliminating the post-alkaline extraction step, its evaporation and subsequent dissolution. The latter aspects are translated into a reduction of sample processing time and, consequently, a higher number of samples processed per working session. Finally, it avoids the use of alkalis and reduces the environmental impact as it generates fewer chemical wastes.

Prior to undertaking enzymatic approaches, a considerable effort was made to adapt previously published analytical conditions to the mass spectrometer using underivatized samples $[26,39,42]$. Since the source temperature should be higher than $50^{\circ} \mathrm{C}$ to avoid operating problems involving the mass spectrometer, no ammonium adducts were observed. Despite this circumstance, the mass spectra of $25-\mathrm{HC}$ and $27-\mathrm{HC}$ could be used to monitor these metabolites by single ion recording. Application of previously reported SPE and chromatographic conditions [43] resulted in gradients with higher sensitivities, suitable for working with $100 \mu \mathrm{L}$ samples. Likewise, using this formic acid-methanol gradient, Narayanaswamy et al. were able to analyze $200 \mu \mathrm{L}$ samples with no need for derivatization or the use of ammonium adducts [21]. These simplifications may facilitate clinical and experimental work.

The proposed enzymatic method shows an important reduction of chromatographic unknown compounds compared to alkaline hydrolysis. Widely used to cleave hydroxycholesterol esters, alkaline hydrolysis is the most controversial step and probably the major cause of their formation because of thermal degradation and the alkaline environment, which can degrade cholesterol and other products [44]. Regarding thermal degradation, it has been shown that the lower the hydrolysis temperature, the fewer the degradation products observed $[34,45,46]$. The presence of those unknown compounds 
A

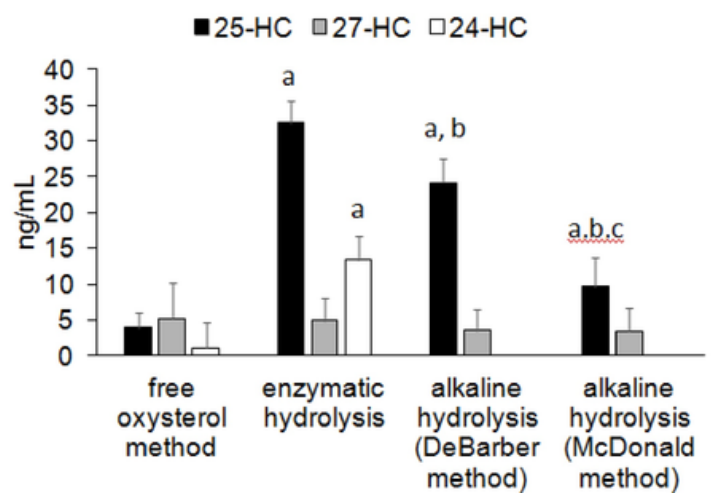

B

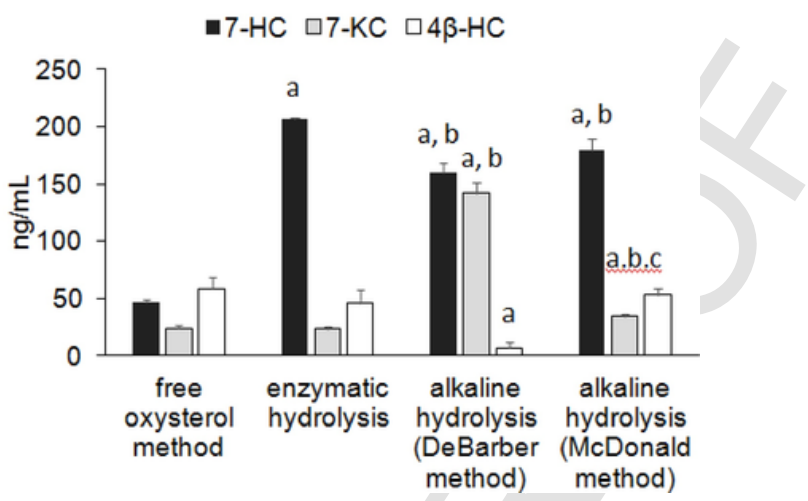

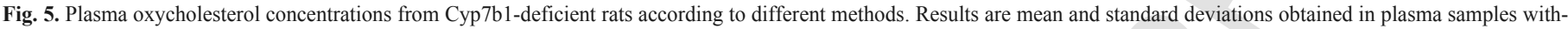

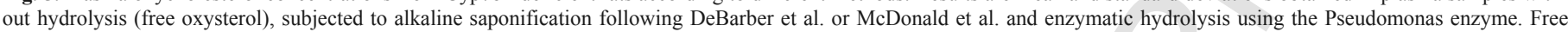

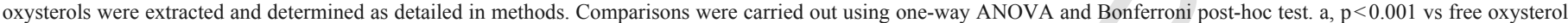
method; b, p $<0.001$ vs free enzymatic hydrolysis and c p $<0.001$ vs DeBarber alkaline hydrolysis.

Table 3

Plasma levels of total oxysterols from different species obtained by the enzymatic procedure.

\begin{tabular}{llllll}
\hline & $\begin{array}{l}\text { Human } \\
\left(\mathrm{ng} \mathrm{mL}^{-1}\right)\end{array}$ & $\begin{array}{l}\text { Apoe-deficient } \\
\text { mice }\left(\mathrm{ng} \mathrm{mL}^{-1}\right)\end{array}$ & $\begin{array}{l}\text { Wistar rat } \\
\left(\mathrm{ng} \mathrm{mL}^{-1}\right)\end{array}$ & $\begin{array}{l}\text { Wild-type } \\
\text { Fisher rat } \\
\left(\mathrm{ng} \mathrm{mL}^{-1}\right)\end{array}$ & $\begin{array}{l}\text { Cyp7b1-KO } \\
\text { Fisher rat } \\
\left(\mathrm{ng} \mathrm{mL}^{-1}\right)\end{array}$ \\
\hline 24-HC & 40.5 & 3.8 & 3.0 & 2.7 & 13.4 \\
25-HC & 6.8 & 3.3 & 3.4 & 2.3 & 32.5 \\
27-HC & 88.5 & 54.2 & 27.9 & 3.1 & 4.9 \\
7-HC & 36.8 & 75.1 & 10.0 & 12.6 & 206.2 \\
7-KC & 15.6 & 10.6 & 6.2 & 13.4 & 23.1 \\
4-BHC & 30.4 & 25.1 & 55.2 & 52.9 & 45.6 \\
\hline
\end{tabular}

may influence the background and, thus, the chromatographic baseline used for calculations, therefore biasing analyte concentrations or even preventing their calculation. This is particularly relevant for oxysterols, which are found in very low concentrations. To overcome these problems, these compounds are derivatized [35,47-50], this approach gives low LOD and high sensitivity and also less background for quantitative measurement. However, the latter requires another step in sample processing, which further increases the time and cost of analysis. The use of cholesterol esterases to hydrolyze hydroxycholesterol esters, without requiring an alkaline environment or high temperatures, provides an optimal operational setting to overcome those drawbacks and their consequences. Therefore, a cleaner baseline that facilitates calculations was obtained.

An additional disadvantage of alkaline hydrolysis is the dependence on the protocol used. As shown in Fig. 3, with pathological samples, the method proposed by Mcdonald et al. [26] did not achieve complete hydrolysis of cholesterol esters. This could explain the lower levels of 25-HC obtained with the Mcdonald method (Fig. 5). However, it resulted in 27-HC levels similar to those obtained with the enzymatic procedure (Fig. 5). The other alkaline protocol proposed [32] yielded higher amounts of 7-KC. This discrepancy between the two protocols could be attributed to sample treatment under the specific conditions of this procedure, lending further support to the hypothesis of the possible generation of 7-KC during saponification in an alkaline medium, with high temperatures and high levels of cholesterol in the sample, as has been proposed [34].

The proposed enzymatic method requires incubation with surfactants to improve activities of the enzymes in the assay. This could be explained by its role in disassembling the plasma lipoproteins and facilitating enzyme access to their core, where esterified compounds are found, or blocking other hydroxycholesterol-protein interactions that might preclude access of cholesterol esterases. The enzymatic method for the determination of total oxysterols in plasma fulfills acceptable analytical goals for this kind of samples [51] in terms of linear range, limits of detection and quantification, repeatability, intermediate precision, overall efficiency and accuracy (Table 2). These parameters were satisfactory due to the use of the deuterated internal standard, 25-HC(d6), which compensates for the disturbances throughout sample treatment and instrumental analysis (especially during the ionization process) [43,52]. Regarding to 24-HC, 7-HC, $4 \beta-\mathrm{HC}$ and $7-\mathrm{KC}$, we did not use their deuterated internal standards as it should be because when we used $25-\mathrm{HC}(\mathrm{d} 6)$ and $27-\mathrm{HC}(\mathrm{d} 6)$ as internal standards consistent results and good recovery were obtained (Table 2).

A number of features of enzymatic hydrolysis are translated into the simplification of sample processing, and constitute further advantages over the alkaline methods. For example, the hydrolysis step of enzymatic processing was carried out directly on the plasma sample. Thus, an evaporation and dissolution step required in alkaline hydrolysis was eliminated. In addition, we found that incubations for periods longer than $120 \mathrm{~min}$ were clearly detrimental, even when they were carried out at $37^{\circ} \mathrm{C}$, a circumstance that defines a time frame for sample processing. This effect was particularly relevant for the 25-HC determination since, beyond that point, this compound may be degraded (data not shown). However, under the described conditions, $27-\mathrm{HC}$ was quite stable in the interval from 120 to $240 \mathrm{~min}$. The above experiment also suggests that, because of the need to avoid possible degradation, 25 -HC determination is more demanding than that of 27-HC. It is interesting to note that Cyp7b1-deficient rats accumulate $25-\mathrm{HC}$ but not $27-\mathrm{HC}$, a fact that would point to the former as the preferential substrate for this enzyme, in agreement with the data of Cui et al. obtained from the structural characterization of human CYP7B1 [53]. In patients having mutations in CYP7B1 [25], the plasma levels of 25 -HC were increased about 100 -fold while those of $27-\mathrm{HC}$ were only elevated 6-9 times. However, mice lacking CYP7B1 showed a similar increase of both oxysterols [24]. The ratios of $27-\mathrm{HC}$ to $25-\mathrm{HC}$ obtained by the enzymatic method for human and mouse samples (Table 3) were similar to those reported by Quehenberger et al. [54] and Li-Hawkins et al. [24], respectively. These data indicate that the phenotypic level of oxysterol present in CYP7B1 mutants may be dependent on genetic background. In fact, 
wild-type Fisher rat showed a low level of 27-HC compared to Wistar rats.

In conclusion, the proposed enzymatic method provides cleaner chromatograms, quantifies lower concentrations of oxysterols without using derivatization, and is as accurate as the methods currently used. It also represents a simplification in sample processing by avoiding high temperatures, alkaline hydrolysis and further purification steps. Thus, more samples may be processed within a given time period, without using hazardous alkalis, a circumstance that results in clear benefits for operators and in reduced costs. Moreover, an increase in the number of samples processed, make it suitable for large scale clinical samples and for the measurement of oxysterols in tissues. For all these reasons, the proposed simplification is expected to expand the determination of these compounds to investigate their role in several diseases.

\section{Conflict of interest}

The Medical College of Wisconsin receives royalties on sales of genetically modified rats from Transposagen BioPharmaceuticals, Inc.

\section{Acknowledgments}

We thank Martha Messman for her assistance in manuscript editing. This research was supported by grants from the Spanish Ministerio de Economía y Competitividad, Agencia Estatal de Investigación-European Regional Development Fund (SAF2013-41651-R and SAF2016-75441-R) and the European Social Fund-Gobierno de Aragón (B-69 and GUIA group T-10). CIBER Fisiopatología de la Obesidad y Nutrición (CIBEROBN) is an initiative of ISCIII.

\section{References}

[1] A.R. Tall, L. Yvan-Charvet, Cholesterol, inflammation and innate immunity, Nat. Rev. Immunol. 15 (2) (2015) 104-116.

[2] R. Lappano, A.G. Recchia, E.M. De Francesco, T. Angelone, M.C. Cerra, D. Picard, M. Maggiolini, The cholesterol metabolite 25-hydroxycholesterol activates estrogen receptor alpha-mediated signaling in cancer cells and in cardiomyocytes, PLoS One 6 (1) (2011) e16631.

[3] A. Appukuttan, S.A. Kasseckert, S. Kumar, H.P. Reusch, Y. Ladilov, Oxysterol-induced apoptosis of smooth muscle cells is under the control of a soluble adenylyl cyclase, Cardiovasc. Res. 99 (4) (2013) 734-742.

[4] N. Shibata, A.F. Carlin, N.J. Spann, K. Saijo, C.S. Morello, J.G. McDonald, C.E. Romanoski, M.R. Maurya, M.U. Kaikkonen, M.T. Lam, A. Crotti, D. Reichart, J.N. Fox, O. Quehenberger, C.R. Raetz, M.C. Sullards, R.C. Murphy, A.H. Merrill Jr., H.A. Brown, E.A. Dennis, E. Fahy, S. Subramaniam, D.R. Cavener, D.H Spector, D.W. Russell, C.K. Glass, 25-Hydroxycholesterol activates the integrated stress response to reprogram transcription and translation in macrophages, J. Biol. Chem. 288 (50) (2013) 35812-35823.

[5] E.S. Gold, S.A. Ramsey, M.J. Sartain, J. Selinummi, I. Podolsky, D.J. Rodriguez, R.L. Moritz, A. Aderem, ATF3 protects against atherosclerosis by suppressing 25-hydroxycholesterol-induced lipid body formation, J. Exp. Med. 209 (4) (2012) 807-817.

[6] A. Reboldi, E.V. Dang, J.G. McDonald, G. Liang, D.W. Russell, J.G. Cyster, Inflammation. 25-Hydroxycholesterol suppresses interleukin-1-driven inflammation downstream of type I interferon, Science 345 (6197) (2014) 679-684.

[7] G.T. Vatassery, H.T. Quach, W.E. Smith, F. Ungar, Oxidation of cholesterol in synaptosomes and mitochondria isolated from rat brains, Lipids 32 (8) (1997) 879-886.

[8] J.Y. Chang, L.Z. Liu, Peroxisome proliferator-activated receptor agonists prevent 25-OH-cholesterol induced c-jun activation and cell death, BMC Pharmacol. 1 (2001) 10.

[9] J.Y. Chang, L.Z. Liu, 25-Hydroxycholesterol causes death but does not prevent nerve growth factor-induced neurite outgrowth in PC12 cells, Neurochem. Int. 31 (4) (1997) 517-523.

[10] J.Y. Chang, K.D. Phelan, L.Z. Liu, Neurotoxicity of 25-OH-cholesterol on NGF-differentiated PC12 cells, Neurochem. Res. 23 (1) (1998) 7-16.
[11] J.Y. Chang, K.D. Phelan, J.A. Chavis, Neurotoxicity of 25-OH-cholesterol on sympathetic neurons, Brain Res. Bull. 45 (6) (1998) 615-622.

[12] J.Y. Chang, L.Z. Liu, Toxicity of cholesterol oxides on cultured neuroretinal cells, Curr. Eye Res. 17 (1) (1998) 95-103.

[13] J.Y. Chang, L.Z. Liu, Neurotoxicity of cholesterol oxides on cultured cerebellar granule cells, Neurochem. Int. 32 (4) (1998) 317-323.

[14] C. Ullrich, M. Pirchl, C. Humpel, Effects of cholesterol and its $24 \mathrm{~S}-\mathrm{OH}$ and 25-OH oxysterols on choline acetyltransferase-positive neurons in brain slices, Pharmacology 86 (1) (2010) 15-21.

[15] S.M. Kim, M.Y. Noh, H. Kim, S.Y. Cheon, K.M. Lee, J. Lee, E. Cha, K.S. Park, K.W. Lee, J.J. Sung, S.H. Kim, 25-Hydroxycholesterol is involved in the pathogenesis of amyotrophic lateral sclerosis, Oncotarget (2017).

[16] M.E. Baker, K.Y. Uh, C. Chandsawangbhuwana, 3D models of human ERalpha and ERbeta complexed with 5-androsten-3beta,17beta-diol, Steroids 77 (12) (2012) 1192-1197.

[17] M.V. Fournier, F. Guimaraes da Costa, M.E. Paschoal, L.V. Ronco, M.G. Carvalho, A.B. Pardee, Identification of a gene encoding a human oxysterol-binding protein-homologue: a potential general molecular marker for blood dissemination of solid tumors, Cancer Res. 59 (15) (1999) 3748-3753.

[18] S. Banerji, M. Ngo, C.F. Lane, C.A. Robinson, S. Minogue, N.D. Ridgway, Oxysterol binding protein-dependent activation of sphingomyelin synthesis in the golgi apparatus requires phosphatidylinositol 4-kinase IIalpha, Mol. Biol. Cell 21 (23) (2010) 4141-4150.

[19] H.L. Wang, Y.Y. Wang, X.G. Liu, S.H. Kuo, N. Liu, Q.Y. Song, M.W. Wang, Cholesterol, 24-Hydroxycholesterol, and 27-Hydroxycholesterol as surrogate biomarkers in cerebrospinal fluid in mild cognitive impairment and alzheimer's disease: a meta-Analysis, J. Alzheimers Dis. 51 (1) (2016) 45-55.

[20] G. Testa, E. Staurenghi, C. Zerbinati, S. Gargiulo, L. Iuliano, G. Giaccone, F. Fanto, G. Poli, G. Leonarduzzi, P. Gamba, Changes in brain oxysterols at different stages of Alzheimer's disease: their involvement in neuroinflammation, Redox Biol. 10 (2016) 24-33.

[21] R. Narayanaswamy, V. Iyer, P. Khare, M.L. Bodziak, D. Badgett, R. Zivadinov, B. Weinstock-Guttman, T.C. Rideout, M. Ramanathan, R.W. Browne, Simultaneous determination of oxysterols, cholesterol and 25-hydroxy-vitamin D3 in human plasma by LC-UV-MS, PLoS One 10 (4) (2015) e0123771.

[22] A.F. Aubry, B. Dean, U. Diczfalusy, A. Goodenough, A. Iffland, J. McLeod, N. Weng, Z. Yang, Recommendations on the development of a bioanalytical assay for 4beta-Hydroxycholesterol, an emerging endogenous biomarker of CYP3A activity, AAPS J. 18 (5) (2016) 1056-1066.

[23] J. Mao, I. Martin, J. McLeod, G. Nolan, R. van Horn, M. Vourvahis, Y.S. Lin, Perspective: 4beta-hydroxycholesterol as an emerging endogenous biomarker of hepatic CYP3A, Drug Metabol. Rev. 49 (1) (2017) 18-34.

[24] J. Li-Hawkins, E.G. Lund, S.D. Turley, D.W. Russell, Disruption of the oxysterol 7alpha-hydroxylase gene in mice, J. Biol. Chem. 275 (22) (2000) 16536-16542.

[25] R. Schule, T. Siddique, H.X. Deng, Y. Yang, S. Donkervoort, M. Hansson, R.E. Madrid, N. Siddique, L. Schols, I. Bjorkhem, Marked accumulation of 27-hydroxycholesterol in SPG5 patients with hereditary spastic paresis, J. Lipid Res. 51 (4) (2010) 819-823.

[26] J.G. McDonald, D.D. Smith, A.R. Stiles, D.W. Russell, A comprehensive method for extraction and quantitative analysis of sterols and secosteroids from human plasma, J. Lipid Res. 53 (7) (2012) 1399-1409.

[27] E.G. Bligh, W.J. Dyer, A rapid method of total lipid extraction and purification, Can. J. Biochem. Physiol. 37 (8) (1959) 911-917.

[28] J. Folch, M. Lees, G.H. Sloane Stanley, A simple method for the isolation and purification of total lipides from animal tissues, J. Biol. Chem. 226 (1) (1957) 497-509.

[29] S. Dzeletovic, O. Breuer, E. Lund, U. Diczfalusy, Determination of cholesterol oxidation products in human plasma by isotope dilution-mass spectrometry, Anal. Biochem. 225 (1) (1995) 73-80.

[30] D. Lutjohann, O. Breuer, G. Ahlborg, I. Nennesmo, A. Siden, U. Diczfalusy, I. Bjorkhem, Cholesterol homeostasis in human brain: evidence for an age-dependent flux of 24S-hydroxycholesterol from the brain into the circulation, Proc. Natl. Acad. Sci. U. S. A. 93 (18) (1996) 9799-9804.

[31] L. Yu, K. von Bergmann, D. Lutjohann, H.H. Hobbs, J.C. Cohen, Selective sterol accumulation in ABCG5/ABCG8-deficient mice, J. Lipid Res. 45 (2) (2004) 301-307.

[32] A.E. DeBarber, D. Lutjohann, L. Merkens, R.D. Steiner, Liquid chromatography-tandem mass spectrometry determination of plasma 24S-hydroxycholesterol with chromatographic separation of 25-hydroxycholesterol, Anal. Biochem. 381 (1) (2008) 151-153.

[33] H. Sugimoto, M. Kakehi, Y. Satomi, H. Kamiguchi, F. Jinno, Method development for the determination of 24S-hydroxycholesterol in human plasma without derivatization by high-performance liquid chromatography with tandem mass spectrometry in atmospheric pressure chemical ionization mode, J. Sep. Sci. 38 (20) (2015) 3516-3524. 
[34] P.W. Park, F. Guardiola, S.H. Park, P.B. Addis, Kinetic evaluation of 3 $\beta$-hydroxycholest-5-en-7-one (7-ketocholesterol) stability during saponification, J. Am. Oil Chem. Soc. 73 (1996) 623-629.

[35] W.J. Griffiths, P.J. Crick, Y. Wang, Methods for oxysterol analysis: past, present and future, Biochem. Pharmacol. 86 (1) (2013) 3-14.

[36] R. Sidhu, H. Jiang, N.Y. Farhat, N. Carrillo-Carrasco, M. Woolery, E. Ottinger, F.D. Porter, J.E. Schaffer, D.S. Ory, X. Jiang, A validated LC-MS/MS assay for quantification of 24(S)-hydroxycholesterol in plasma and cerebrospinal fluid, J. Lipid Res. 56 (6) (2015) 1222-1233.

[37] B. Lu, A.M. Geurts, C. Poirier, D.C. Petit, W. Harrison, P.A. Overbeek, C.E. Bishop, Generation of rat mutants using a coat color-tagged Sleeping Beauty transposon system, Mamm. Genome 18 (5) (2007) 338-346.

[38] H. Trufelli, P. Palma, G. Famiglini, A. Cappiello, An overview of matrix effects in liquid chromatography-mass spectrometry, Mass Spectrom. Rev. 30 (3) (2011) 491-509.

[39] V.V. Bandaru, N.J. Haughey, Quantitative detection of free 24S-hydroxycholesterol, and 27-hydroxycholesterol from human serum, BMC Neurosci. 15 (2014) 137.

[40] H. Roberg-Larsen, C. Vesterdal, S.R. Wilson, E. Lundanes, Underivatized oxysterols and nanoLC-ESI-MS: a mismatch, Steroids 99 (2015) 125-130.

[41] A.E. Stepien, M. Gonchar, A simple method for the determination of the cholesterol esterase activity, Acta Biochim. Pol. 60 (3) (2013) 401-403.

[42] R. Karuna, I. Christen, A.W. Sailer, F. Bitsch, J. Zhang, Detection of dihydroxycholesterols in human plasma using HPLC-ESI-MS/MS, Steroids 99 (Pt B) (2015) 131-138.

[43] I. Mendiara, K. Bentayeb, C. Nerín, C. Domeño, Online solid-phase extraction-liquid chromatography-mass spectrometry to determine free sterols in $\mathrm{Hu}$ man serum, Talanta 132 (2015) 690-697.

[44] T.P. Busch, A.J. King, Artifact generation and monitoring in analysis of cholesterol oxide products, Anal. Biochem. 388 (1) (2009) 1-14.

[45] N.C. van de Merbel, K.J. Bronsema, M.W. van Hout, R. Nilsson, H. Sillen, A validated liquid chromatography-tandem mass spectrometry method for the quantitative determination of 4beta-hydroxycholesterol in human plasma, $\mathrm{J}$ Pharm. Biomed. Anal. 55 (5) (2011) 1089-1095.

[46] Y. Xu, Y. Yuan, L. Smith, R. Edom, N. Weng, R. Mamidi, J. Silva, D.C. Evans, H.K. Lim, LC-ESI-MS/MS quantification of 4beta-hydroxycholesterol and cho- lesterol in plasma samples of limited volume, J. Pharm. Biomed. Anal. 85 (2013) $145-154$.

[47] X. Jiang, R. Sidhu, F.D. Porter, N.M. Yanjanin, A.O. Speak, D.T. te Vruchte, F.M. Platt, H. Fujiwara, D.E. Scherrer, J. Zhang, D.J. Dietzen, J.E. Schaffer, D.S. Ory, A sensitive and specific LC-MS/MS method for rapid diagnosis of Niemann-Pick C1 disease from human plasma, J. Lipid Res. 52 (7) (2011) 1435-1445.

[48] H.F. Schott, D. Lutjohann, Validation of an isotope dilution gas chromatography-mass spectrometry method for combined analysis of oxysterols and oxyphytosterols in serum samples, Steroids 99 (2015) 139-150.

[49] P.J. Crick, T. William Bentley, J. Abdel-Khalik, I. Matthews, P.T. Clayton, A.A. Morris, B.W. Bigger, C. Zerbinati, L. Tritapepe, L. Iuliano, Y. Wang, W.J. Griffiths, Quantitative charge-tags for sterol and oxysterol analysis, Clin. Chem. 61 (2) (2015) 400-411.

[50] Z. Pataj, G. Liebisch, G. Schmitz, S. Matysik, Quantification of oxysterols in human plasma and red blood cells by liquid chromatography high-resolution tandem mass spectrometry, J. Chromatogr. A 1439 (2016) 82-88.

[51] M. Rambla-Alegre, J. Esteve-Romero, S. Carda-Broch, Is it really necessary to validate an analytical method or not? That is the question, J. Chromatogr. A 1232 (0) (2012) 101-109.

[52] O.A. Ismaiel, M.S. Halquist, M.Y. Elmamly, A. Shalaby, H.T. Karnes, Monitoring phospholipids for assessment of ion enhancement and ion suppression in ESI and APCI LC/MS/MS for chlorpheniramine in human plasma and the importance of multiple source matrix effect evaluations, J. Chromatogr. B: Anal. Technol. Biomed. Life Sci. 875 (2) (2008) 333-343.

[53] Y.L. Cui, J.L. Zhang, Q.C. Zheng, R.J. Niu, Y. Xu, H.X. Zhang, C.C. Sun, Structural and dynamic basis of human cytochrome P450 7B1: a survey of substrate selectivity and major active site access channels, Chemistry 19 (2) (2012) $549-557$.

[54] O. Quehenberger, A.M. Armando, A.H. Brown, S.B. Milne, D.S. Myers, A.H. Merrill, S. Bandyopadhyay, K.N. Jones, S. Kelly, R.L. Shaner, C.M. Sullards, E. Wang, R.C. Murphy, R.M. Barkley, T.J. Leiker, C.R. Raetz, Z. Guan, G.M. Laird, D.A. Six, D.W. Russell, J.G. McDonald, S. Subramaniam, E. Fahy, E.A. Dennis, Lipidomics reveals a remarkable diversity of lipids in human plasma, J. Lipid Res. 51 (11) (2010) 3299-3305. 